\title{
CARACTERÍSTICAS COMERCIAIS DA SALSA EM AMBIENTES COBERTOS COM MALHAS DE SOMBREAMENTO E FOTO CONVERSORA DURANTE O VERÃO NA REGIÃO DE IMARUÍ, SANTA CATARINA
}

\author{
Marcos Laurentino ${ }^{1}$, Rosandro Boligon Minuzzi ${ }^{2}$
}

\begin{abstract}
RESUMO - O objetivo deste estudo foi avaliar as características comerciais de salsa durante o verão na região de Imaruí, Santa Catarina. O delineamento experimental foi em blocos completos casualizados com cinco tratamentos, sendo o cultivo feito em ambiente coberto com malha preta e a ChromatiNet ${ }^{\circledR}$ vermelha, nas graduações $35 \%$ e $50 \%$ e em céu aberto. Após 38 dias do transplante das mudas para os canteiros, foi realizada a contagem de plantas vivas em cada unidade experimental, assim como a coleta de amostras de plantas para medição da área foliar e o peso total de massa fresca produzida em cada tratamento. As salsas cultivadas em todos os ambientes com malhas tiveram diferença significativa sobre a testemunha no número de plantas vivas. As malhas pretas de $35 \%$ e $50 \%$ obtiveram os melhores resultados, sendo as mais indicadas para o cultivo de salsa nas condições climáticas durante o verão em Imaruí.
\end{abstract}

Palavras chave: ambiente protegido, Petroselinum crispum, radiação solar.

\section{COMMERCIAL CHARACTERISTICS OF THE PARSLEY IN ENVIRONMENTS COVERED WITH SHADING MESHES AND PHOTO CONVERTER DURING THE SUMMER IN THE REGION OF IMARUÍ, SANTA CATARINA}

\begin{abstract}
The objective of this study was to evaluate the commercial characteristics of parsley during the summer in the region of Imaruí, Santa Catarina. The experimental design was in a randomized complete block with five treatments, the cultivation being done in a covered environment with black mesh and the ChromatiNet ${ }^{\circledR}$ red, in the graduations $35 \%$ and $50 \%$ and in open sky. After 38 days of transplantation of the seedlings for the beds, count of live plants in each experimental unit, as well as the collection of plant samples to measure the leaf area and the total weight of fresh mass produced in each treatment. Sauces grown in all mesh environments had a significant difference on the number of live plants. The black meshes of $35 \%$ and $50 \%$ obtained the best results, being the most indicated for the cultivation of parsley in the climatic conditions during the summer in Imaruí.
\end{abstract}

Keywords: greenhouse, Petroselinum crispum, solar radiation.

\section{INTRODUÇÃO}

A salsa ou salsinha Petroselinum crispum, pertence à família das Apiáceas e é uma hortaliça folhosa, muito utilizada como condimento na culinária brasileira e também no mundo (Escobar et al., 2010). Adaptam-se bem em ambientes amenos com temperaturas entre 10 e $24^{\circ} \mathrm{C}$, enquanto fora desse limite a sua produção é prejudicada (Braga et al., 2014). A planta se adapta bem a solos areno-argilosos com pH entre 5,8 e 6,8, com início de produção variando entre 50 e 90 dias após a semeadura (Escobar et al., 2010).

O cultivo durante o verão dessas hortaliças na região litorânea de Santa Catarina tem sido prejudicado pelo aumento demasiado da evapotranspiração e temperatura do ar. Alvares et al. (2014), atestam essa informação mostrando que o litoral catarinense possui

\footnotetext{
${ }^{1}$ Agrônomo na empresa Verduras Laurentino, Estrada Geral Riacho Ana Matias, 88770-000, Imaruí, SC marcosagro@hotmail.com

${ }_{2}^{2}$ Professor do Departamento de Engenharia Rural, Universidade Federal de Santa Catarina, Av. Admar Gonzaga, 1346, Itacorubi, 88034-001, Florianópolis, SC.rosandro.minuzzi@ufsc.br
} 
temperaturas elevadas no verão, que podem superar facilmente as máximas toleradas pela salsa. Um problema comum é o enraizamento após o transplante em solos com temperaturas elevadas, assim como, o apodrecimento das raízes das plantas já em produção.

O cultivo protegido de hortaliças tem sido utilizado desde os anos 1980 no Sul e Sudeste do Brasil, promovendo um ambiente propício para o cultivo, podendo assim se obter maior qualidade e uniformidade da produção (Rocha, 2007). A utilização de malhas tem sido empregada para viabilizar a produção de diversas hortaliças em regiões de clima com grande incidência de radiação solar e altas temperaturas (Bezerra Neto et al., 2005).

De acordo com Bezzera Neto et al. (2005) as malhas são telas de polipropileno que proporcionam sombreamento e podem ser utilizadas em estufas ou em campo aberto. Amalha diminui a incidência de radiação solar sobre as plantas, modificando a taxa fotossintética e o microclima onde a planta está sendo cultivada (Ribeiro et al., 2007).

Existem diferentes tipos de malhas em função dos níveis de sombreamento, sendo os mais facilmente encontrados de $35 \%$ e $50 \%$ de sombra. O mercado ainda apresenta outras malhas com diferentes objetivos, como por exemplo, a ChromatiNet ${ }^{\circledR}$ vermelha, que faz conversão do espectro de luz solar, potencializando o espectro nas ondas do vermelho e vermelho distante além de maximizar a distribuição da luz difusa, possibilitando melhor aproveitamento pelas plantas (Costa et al., 2011b).

Tendo em vista a dificuldade do cultivo de salsa no verão no litoral de Santa Catarina, o presente trabalho tem como objetivo avaliar as características comerciais da salsa cultivada no verão em ambientes com diferentes tipos de malhas na região de Imaruí, litoral de Santa Catarina.

\section{MATERIAL E MÉTODOS}

O experimento foi conduzido entre o período de $1^{\circ}$ de fevereiro de 2018 a 10 de março do mesmo ano, na cidade de Imaruí, localizada nas coordenadas geográficas $28^{\circ} 11^{\prime} 12.7^{\prime \prime S}$ e $48^{\circ} 47^{\prime} 18.9^{\prime \prime} \mathrm{W}$ e altitude de 6 metros.

A análise química do solo feita previamente a implantação do experimento possuía: $\mathrm{pH}$ em água 5,5,
P $238 \mathrm{mg} \mathrm{dm}^{-3}, \mathrm{~K} 184 \mathrm{mg} \mathrm{dm}^{-3}, 2 \%$ de matéria orgânica, Ca 3,5 cmolc d $^{-1}, \mathrm{Mg} \mathrm{1,2}$ cmolc dm $^{-1}$, CTC (pH7,0) 13,17 cmolc dm ${ }^{-3}$, V 39,26\%.

O delineamento experimental foi em Blocos Casualizados, com quatro repetições e cinco tratamentos: malha preta e ChromatiNet ${ }^{\circledR}$ vermelha, nas graduações $35 \%$ e $50 \%$ e céu aberto, sendo considerado como testemunha $(\mathrm{T})$. Foi utilizada a cultivar salsa da roça, com sementes da marca Horticeres ${ }^{\circledR}$ e mudas cultivadas em ambiente protegido (estufa agrícola) e sem a necessidade de debaste.

Depois de transcorridos 38 dias do transplante das mudas para os canteiros foi feito a contagem de plantas vivas em cada unidade experimental, assim como a coleta de amostras de plantas para medição da área foliar. Foi obtido também o peso total de massa fresca produzida em cada tratamento.

Os canteiros e os sulcos para passagem foram confeccionados com o auxílio de um trator de rabiças, que revolveu o solo já previamente adubado, de acordo com o recomendado para a cultura no Manual de Calagem e Adubação para os estados do Rio Grande do Sul e Santa Catarina (2016). Após o revolvimento do solo e a confecção dos sulcos, com auxílio de rastelos, os canteiros foram nivelados, e passaram a compor uma área de $12 \mathrm{~m}$ de comprimento, 1,20 $\mathrm{m}$ de largura e $0,25 \mathrm{~m}$ de altura.

As malhas foram cortadas com $3,5 \mathrm{~m}$ de comprimento e 2,5 $\mathrm{m}$ de largura. Foi elaborado um esquema de arco para sustentação das malhas com orientação norte-sul de modo que preenchesse toda área experimental com sombra. Para a estrutura de sustentação foi utilizado barras de ferro de $3 \mathrm{~m}$ de comprimento com bitola de $6,3 \mathrm{~mm}$, sendo instaladas em forma de arco com $0,75 \mathrm{~m}$ de altura no meio da envergadura. Os arcos de ferro foram instalados com espaçamento de $1,5 \mathrm{~m}$ entre eles. A amarração das malhas foi feita em estacas no solo, para que não fosse danificada com o vento. As parcelas ficaram com 1 $m$ de distância entre si dentro do bloco e entre os blocos foi deixado $0,5 \mathrm{~m}$ de espaçamento.

Foram transplantadas 20 mudas para cada parcela e colocadas em 4 linhas, com espaçamento de $0,25 \mathrm{~m}$ entre linha e entre planta. Considerou-se área útil as seis plantas da área central de cada parcela.

Em cada tratamento, foi medida a temperatura mínima 
e máxima do solo a $0,04 \mathrm{~m}$ de profundidade por meio de sensores instalados no meio da parcela.

Foram feitas irrigações diárias, exceto nos dias de chuva. As irrigações ocorreram pela manhã, com a mesma quantidade de água para cada unidade experimental, dosadas com um regador para cada unidade a cada rega. Nos tratamentos com malhas, as plantas ficaram expostas diretamente ao sol apenas nos momentos em que foram feitas as irrigações. Aos 20 dias após o transplante foi efetuado a capina manual para controlar as plantas espontâneas.

Para a determinação da área foliar foi considerado apenas os tratamentos com malha, pois devido à baixa quantidade de plantas vivas ao fim do experimento a céu aberto, não foi possível estender a metodologia de coleta para este tratamento. Na área útil foram coletados os três maiores ramos de cada uma das seis plantas. As folhas foram separadas dos ramos e organizadas em uma folha de papel branca para fotografálas, sendo repetido em todas as parcelas. Para medição da área foliar através das imagens fotográficas utilizouse o programa Easy Leaf Area ${ }^{\circledR}$.

A contagem de plantas vivas foi feita visualmente, considerando planta viva todas as que tinham pelo menos um ramo vivo. Foram verificadas todas as plantas incluindo as da bordadura.

Para a obtenção da massa fresca da parte aérea das plantas vivas também foi incluído as da bordadura. A média das variáveis obtidas da salsa foram submetidas a análise de variância e comparadas estatisticamente ao nível de 5\% de significância pelo teste de Tukey, com o uso do programa Sisvar 5.6®.

\section{RESULTADOS E DISCUSSÃO}

O número médio de plantas vivas no tratamento testemunha (T) foi de 7,75 plantas, seguido pelo tratamento ChromatiNet ${ }^{\circledR}$ vermelha (V35), com 14,25 plantas, a ChromatiNet ${ }^{\circledR}$ vermelha (V50) com 16,5 plantas, e com as maiores médias, a salsa cultivada nas malhas pretos (P50) e (P35), respectivamente, com 19,5 e 19,75 plantas (Figura 1). As médias de plantas vivas entre os tratamentos cobertos não diferenciaram estatisticamente entre si, mas sim, em relação à testemunha que ficou bem abaixo.

Quanto a massa fresca da parte aérea da salsa, os tratamentos com maior peso, foram nos ambientes com P35 (338,75 g) e P50 (307,5 g), que diferiram significativamente da testemunha, seguidos pela massa fresca em V50 e V35 com 202,5 g e 172,5g, respectivamente, e a testemunha com $65 \mathrm{~g}$ que diferiu significativamente apenas das salsas cobertas com a P35 e P50 (Figura 2). Hoepers (2017) também encontrou peso maior para a salsa coberta com malha preta em comparação com à termo refletora e ao tratamento sem cobertura durante o verão. Porém, na primavera, outono e inverno, os melhores resultados foram das plantas em pleno sol.

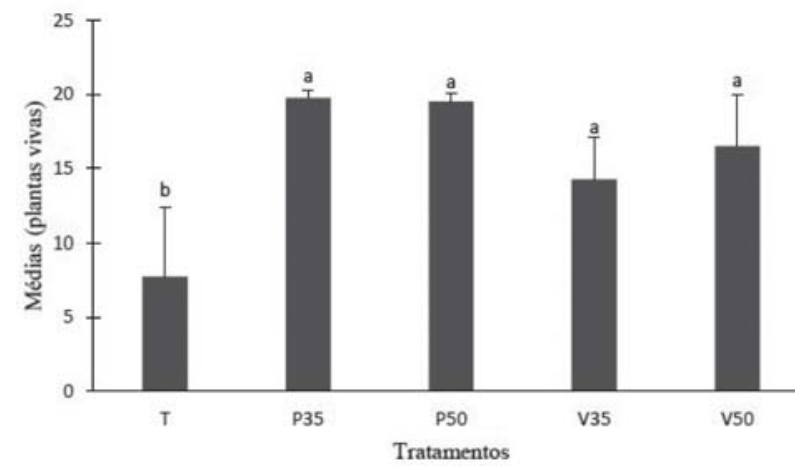

Figura 1 - Média de plantas vivas de salsa, ao fim de 38 dias, nos tratamentos Testemunha (T), ChromatiNet ${ }^{\circ}$ vermelha 35 e 50\%(V35 e V50) e Preto 35 e 50\% (P35 e P50). Médias seguidas da mesma letra não possuem diferenças significativas entre si pelo teste de Tukey $(\mathrm{P}<0,05)$.

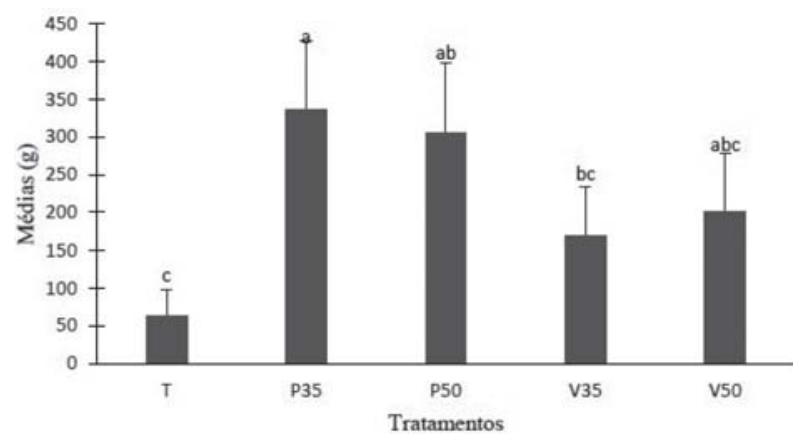

Figura 2 - Massa fresca da parte aérea de salsa, ao fim de 38 dias nos tratamentos Testemunha (T), ChromatiNet ${ }^{2}$ vermelha 35 e $50 \%$ (V35 e V50) e Preto 35 e 50\% (P35 e P50). Médias seguidas da mesma letra não possuem diferenças significativas entre si pelo teste de Tukey $(\mathrm{P}<0,05)$. 
A massa fresca e o número de plantas vivas obtidas, principalmente, com o uso das malhas de sombreamento preta no comparativo com a testemunha atestam as condições climáticas menos propícias no verão para o cultivo da salsa na região. Resultados semelhantes são apontados para outras folhosas como no estudo de Costa et al. (2011a) que encontraram melhores resultados no cultivo de rúcula na malha preta $50 \%$ em comparação a cultivada em pleno sol para Passo Fundo, RS.

Para a área foliar não houve diferença estatisticamente significativa entre os tratamentos cobertos, variando de $190,3 \mathrm{~cm}^{2}$ a $212,7 \mathrm{~cm}^{2}$, obtida em P35 e P50, respectivamente (Figura 3). Como a testemunha obteve uma média de plantas vivas muito abaixo em relação aos tratamentos com cobertura, foi inviável incluir a análise da área foliar. Porém Factor et al. (2008) avaliaram cultivares de salsa sem e com cobertura de agrotêxtil durante o verão na região de Mococa-SP, e nesse caso foi constatada maior área foliar no tratamento sem cobertura. De qualquer forma, considerando a igualdade da área foliar entre os tratamentos, Monteiro (2001) destaca que a absorção de energia luminosa não aumenta indefinidamente com o aumento do índice de área foliar (IAF), isto é, cada planta possui um IAF máximo que maximiza a absorção da luz solar. Assim, presume-se que a diferença observada nas características comerciais previamente analisadas da rúcula não esteve relacionada com a absorção de energia.

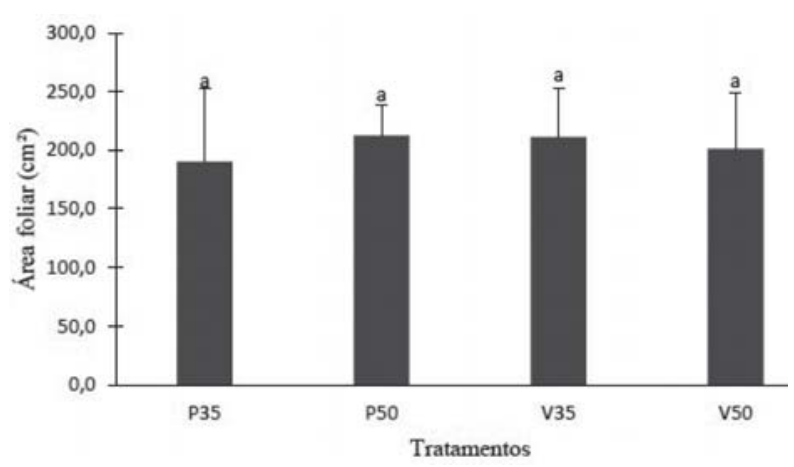

Figura 3 - Área foliar de salsa, ao fim de 38 dias nos tratamentos Testemunha (T), ChromatiNet $\mathbb{R}$ vermelha 35 e $50 \%$ (V35 e V50) e Preto 35 e $50 \%$ (P35 e P50). Médias seguidas da mesma letra não possuem diferenças significativas entre si pelo teste de Tukey $(\mathrm{P}<0,05)$.
$\mathrm{Na}$ testemunha observou-se uma dificuldade de enraizamento da salsa, provavelmente pela maior temperatura máxima diária do solo conforme apresentado na Tabela 1, já que, os registros da temperatura mínima foram estatisticamente iguais. Seguindo a lógica pelo o que propõe o tipo de malha, o solo nos ambientes cobertos com as malhas pretas de sombreamento tiveram as menores temperaturas máximas $\left(30,6^{\circ} \mathrm{C}\right.$ e $\left.31,0^{\circ} \mathrm{C}\right)$ e dispersão dos registros $(3,05 \%$ e 3,37 \%). Por isso, as amplitudes térmicas nos tratamentos seguem as diferenças observadas das temperaturas máximas, isto é, o solo coberto com as malhas pretas $35 \%$ e $50 \%$ tiveram em média uma amplitude térmica menor que os demais tratamentos (Figura 4), o que corrobora com

Tabela 1 - Coeficientes de variação (CV) e médias das temperaturas máximas do solo nos tratamentos Testemunha (T), ChromatiNet ${ }^{\circledR}$ vermelha 35 e $50 \%$ (V35 e V50) e Preto 35 e $50 \%$ (P35 e P50). Médias seguidas da mesma letra não diferem entre si pelo teste de Tukey $(\mathrm{P}<0,05)$

\begin{tabular}{ccc}
\hline Tratamento & Temp. máx $\left({ }^{\circ} \mathrm{C}\right)$ & CV $(\%)$ \\
\hline T & $37,5 \mathrm{c}$ & 4,65 \\
P35 & $30,6 \mathrm{a}$ & 3,05 \\
P50 & $31,0 \mathrm{a}$ & 3,37 \\
V35 & $35,5 \mathrm{bc}$ & 6,31 \\
V50 & $33,8 \mathrm{~b}$ & 3,70 \\
\hline
\end{tabular}

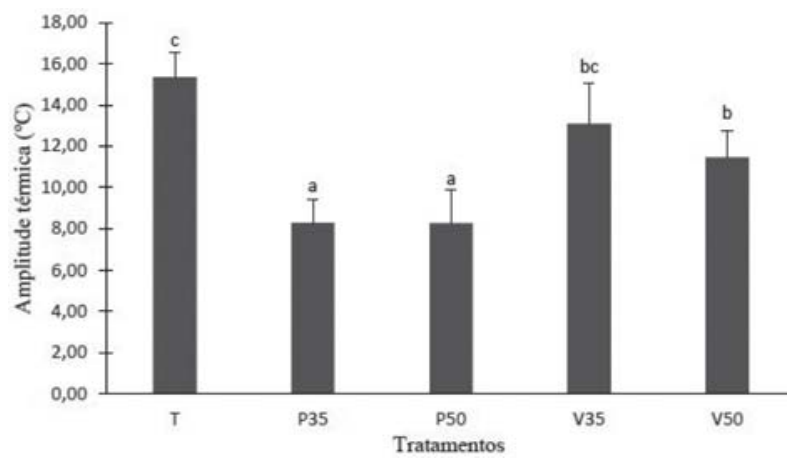

Figura 4 - Amplitude térmica do solo nos tratamentos Testemunha (T), ChromatiNet ${ }^{\circledR}$ vermelha 35 e $50 \%$ (V35 e V50) e Preto 35 e $50 \%$ (P35 e P50). Médias seguidas da mesma letra não possuem diferenças significativas entre si pelo teste de Tukey $(\mathrm{P}<0,05)$. 
Pezzopane et al. (2004) que também observaram na área com sombreamento uma menor evapotranspiração, por haver menor incidência de radiação solar direta.

Notou-se que o cultivo da salsa nas condições meteorológicas apresentadas típicas de verão, a temperatura do solo mais baixa proporcionada pela malha preta foi mais eficiente do que a qualidade de radiação solar proporcionada pela malha foto conversora vermelha. Marenco e Lopes (2009) detalham a absorção e dissipação dos diferentes espectros da energia solar pelas plantas, como ao explicarem que a absorção da luz vermelha é mais eficiente para a ocorrência do processo fotoquímico, embora possua menos energia que a luz azul.

Num contexto geral, além da salsa ter tido melhor desempenho nos ambientes cobertos com malha de sombreamento preta, o seu menor custo em relação à vermelha foto conversora, ratifica como a melhor indicação de uso durante o verão na região do litoral sul de Santa Catarina, evitando perdas no cultivo até então observadas nesta época do ano.

\section{CONCLUSÕES}

O uso das malhas de sombreamento $35 \%$ e $50 \%$ e foto conversora vermelha $50 \%$ favorecem o desenvolvimento de características comerciais em plantas de salsa.

O uso da malha preta $35 \%$ ou $50 \%$ é indicado para o cultivo de salsa durante o verão no litoral de Santa Catarina.

\section{LITERATURA CITADA}

ALVARES, C.A.; STAPE, J.L.; SENTELHAS, P.C. et al. Köppen's climate classification map for Brazil. Meteorologische Zeitschrift, v.22, n.6, p.711-728, 2014.

BEZERRA NETO, F.; ROCHA, R.H.C.; ROCHA, R.C.C. et al. Sombreamento para produção de mudas de alface em alta temperatura e ampla luminosidade. Horticultura Brasileira, v.23, n.1, p.133-137, 2005.

BRAGA, A.H.; SEABRA JÚNIOR, S.; PONCE, F.S. et al. Desempenho de cultivares de salsa (Petroselinum crispum) sob telas de sombreamento, termo-refletoras e campo aberto. Cultivando o Saber, v.7, n.4, p.332-342, 2014.
COSTA, C.M.F. da; SEABRA JÚNIOR, S.; ARRUDA, G.R. et al. Desempenho de cultivares de rúcula sob telas de sombreamento e campo aberto. Ciências Agrárias, v.32, n.1, p.93102, 2011a.

COSTA, R.C. da; CALVETE, E.O.; REGINATTO, F.H. et al. Telas de sombreamento na produção de morangueiro em ambiente protegido. Horticultura Brasileira, v.29, n.1, p.98-102, 2011b.

ESCOBAR, Á.C.N.; NASCIMENTO, A.L.; GOMES, J.G. et al. Avaliação da produtividade de três cultivares de salsa em função de diferentes substratos. Horticultura Brasileira, v.28, n.2, p.2671-2676, 2010.

FACTOR, T.L.; PURQUERIO, L.F.V.; LIMA JÚNIOR, S. et al. Produção de salsa em função do período de cobertura com agrotêxtil. Horticultura Brasileira, v.26, n.2, p.28-32, 2008.

HOEPERS, L.M.L. Crescimento de cultivares de salsa (Petroselinum crispum) em condições de sombreamento e a pleno sol. Dissertação (Mestrado em Agronomia). Marechal Cândido Rondon, PR: UNIOESTE, 2017. 63p.

MANUAL DE CALAGEM E ADUBAÇÃO PARA OS ESTADOS DO RIO GRANDE DO SUL E DE SANTA CATARINA. 11. ed. Porto Alegre, RS: Sociedade Brasileira de Ciência do Solo, Comissão de Química e Fertilidade do Solo, 2016. 376p.

\section{MARENCO, R.A.; LOPES, N.F. Fisiologia vegetal: fotossíntese, respiração, relações hídricas e nutrição mineral. 3. ed., Viçosa, MG: UFV, 2009. 486p.}

MONTEIRO, M.A. Fundamentos do sensoriamento remoto e metodologias de aplicação. São José dos Campos, SP: INPE, 2001.250p.

PEZZOPANE, J.E.M.; OLIVEIRA, P.C. de; REIS, E.F. dos. et al. Alterações microclimáticas causadas pelo uso de tela plástica. Engenharia Agrícola, v.24, n.1, p.9-15, 2004. 
RIBEIRO, M.C.C.; BENEDITO, C.P.; LIMA, M. do $\mathrm{S}$. et al. Influência do sombrite no desenvolvimento da alface em cultivo hidropônico. Revista Verde, v.2, n.2, p.69-72, 2007.

Recebido para publicação em 16/8/2018 e aprovado em 24/9/2018.
ROCHA, R. de C. Uso de diferentes telas de sombreamento no cultivo protegido do tomateiro. Tese (Doutorado em Agronomia). Botucatu, SP: UNESP, 2007.90p. 